\title{
EROSÃO HÍDRICA EM CAMPO NATIVO SOB DIVERSOS MANEJOS: PERDAS DE ÁGUA E SOLO E DE FÓSFORO, POTÁSSIO E AMÔNIO NA ÁGUA DE ENXURRADA ${ }^{(1)}$
}

\author{
Ildegardis Bertol ${ }^{(2)}$, Ederson Gobbi ${ }^{(3)}$, Fabrício Tondello Barbosa $^{(4)}$, \\ Jorge Paz-Ferreiro ${ }^{(5)}$, Luciano Gebler ${ }^{(6)}$, Júlio César $\operatorname{Ramos}^{(7)} \&$ \\ Romeu de Souza Werner ${ }^{(7)}$
}

\begin{abstract}
RESUMO
Os campos nativos do sul do Brasil são utilizados para o pastejo de bovinos e ovinos. Após o verão, no início da estação fria, a fitomassa excedente do pastejo seca, sendo comum sua queima para facilitar o rebrote da pastagem na primavera. No entanto, a queima da fitomassa mineraliza nutrientes e deixa o solo descoberto, potencializando a erosão hídrica. Este trabalho teve o objetivo de quantificar as perdas totais de água e solo e os teores de $\mathrm{P}, \mathrm{Ke} \mathrm{NH}_{4}{ }^{+}$na água da enxurrada, em campo nativo sobre um Latossolo Bruno aluminoférrico típico. Foram estudados os tratamentos: campo nativo sem queima e sem adubo; campo nativo sem queima e com superfosfato triplo; campo nativo com queima e sem adubo; e campo nativo com queima e com superfosfato triplo. Sobre as parcelas, com $11 \mathrm{~m} \mathrm{de}$ comprimento, na direção do declive, e 3,5 m de largura, aplicou-se uma chuva simulada com intensidade de $75 \mathrm{~mm} \mathrm{~h}^{-1} \mathrm{e}$ duração de $3 \mathrm{~h}$. A queima influenciou a erosão hídrica e as perdas de nutrientes. A queima da fitomassa do campo nativo diminuiu os tempos de início e pico da enxurrada e a infiltração de água no solo, bem como aumentou a taxa máxima de enxurrada, as perdas de água e solo por erosão hídrica e os teores e as perdas totais de $\mathrm{P}, \mathrm{Ke} \mathrm{NH}_{4}{ }^{+}$na água de enxurrada, em relação à ausência da queima. A concentração de sedimentos na enxurrada foi maior no tratamento com queima da fitomassa do que no sem queima. O maior e o menor valor da concentração de sedimentos ocorreram em menor tempo de
\end{abstract}

\footnotetext{
(1) Recebido para publicação em 18 de agosto de 2010 e aprovado em 30 de maio de 2011.

(2) Professor de Uso e Conservação do Solo, Universidade do Estado de Santa Catarina - CAV/UDESC. Caixa Postal 281, CEP 88520-000 Lages (SC). Bolsista do CNPq. E-mail: a2ib@cav.udesc.br

(3) MSc. em Ciência do Solo, CAV/UDESC. E-mail: ederagro@hotmail.com

(4) Doutorando em Manejo do Solo, CAV/UDESC. E-mails: a6ftb@cav.udesc.br; a6rvl@cav.udesc.br

(5) Pesquisador do Centro de Investigaciones Agrárias de Mabegondo (CIAM), La Coruña. E-mail: jpaz@udc.es

(6) Pesquisador da EMBRAPA uva e vinho, Vacaria, RS. E-mail: lugebler@m2net.com.br

(7) Bolsista de Iniciação Científica, AV/UDESC. E-mails: julio.ramos.ta@gmail.com; a6rsw@cav.udesc.br
} 
duração do escoamento superficial no tratamento com queima do que no tratamento sem queima, contribuindo para que a perda total de solo fosse 8,9 vezes maior com a queima do que sem a queima do campo. $O$ teor e a perda total de $P$ na água da enxurrada foram maiores no tratamento com adubo fosfatado do que no tratamento sem adubo, tanto no tratamento com queima da fitomassa quanto no sem queima. Para o $\mathrm{K}$ e o $\mathrm{NH}_{4}^{+}$, os teores e as perdas totais foram maiores no tratamento com queima do que no sem queima. $O$ modelo exponencial do tipo y = $a^{-b x}$ ajustou-se aos teores de $\mathrm{P}, \mathrm{K} \mathrm{e} \mathrm{NH}_{4}{ }^{+}$na água da enxurrada, em relação ao tempo de ocorrência do escoamento superficial $(p<0,01)$.

Termos de indexação: queima de campo, adubação de campo, nutrientes na enxurrada, chuva simulada.

\title{
SUMMARY: WATER EROSION IN NATURAL GRASSLAND UNDER DIFFERENT MANAGEMENTS: WATER AND SOIL LOSSES AND PHOSPHORUS, POTASSIUM AND AMMONIUM IN THE RUNOFF
}

\begin{abstract}
Native pastures in southern Brazil are used for cattle and sheep grazing. The forage offer in the spring-summer season is greater than the animal requirement, so the forage left over is usually burned. Pasture burning mineralizes nutrients and leaves the soil bare, triggering water erosion. This study aimed to quantify total soil and water losses and $\mathrm{P}, \mathrm{K}$ and $\mathrm{NH}_{4}^{+}$ contents in the runoff water from an Oxisol with native pasture. In the treatments, the native pastures, were i) unburned and unfertilized, ii) unburned and P-fertilized, iii) burned and unfertilized, and iv) burned and P-fertilized. Rain was simulated at an intensity of $75 \mathrm{~mm} \mathrm{~h}^{-1}$ and duration of $3 \mathrm{~h}$ on the plots (11 $\mathrm{m}$ long along the slope and $3.5 \mathrm{~m}$ wide). Burning of the native vegetation decreased the times until runoff began and peaked and reduced soil water infiltration, but increased the maximum runoff rate, soil and water losses by water erosion and the $\mathrm{P}, \mathrm{K}$ and $\mathrm{NH}_{4}^{+}$concentration and total losses in the runoff water, compared to no burning. The runoff sediment concentration was higher in the treatment with vegetation burning than without. The highest and lowest values of sediment concentration were detected after a shorter runoff period in the treatment with vegetation burning than in that without, which is related to the 8.9 times higher total soil loss from burnt than from unburnt grassland. The P concentration and total loss in the runoff water were higher in the treatment with than without phosphate fertilizer, in the treatment with burning as well as that without. For $\mathrm{K}$ and the $\mathrm{NH}_{4}^{+}$, the concentration and total losses were higher in the treatment with burning than in that without.

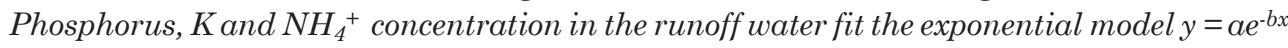
in relation to runoff duration $(p<0.01)$.
\end{abstract}

Index terms: pasture burning, pasture fertilization, nutrients in runoff; simulated rainfall.

\section{INTRODUÇÃO}

As áreas de campo nativo no sul do Brasil, especialmente nos campos de elevada altitude, são tradicionalmente utilizadas para pastejo animal, especialmente com bovinos e ovinos. A espécie vegetal dominante nessas pastagens é uma gramínea, denominada capim-caninha (Andropogon lateralis L.), e seu crescimento vegetativo é abundante na primavera-verão. Nessa época do ano normalmente a oferta de forragem é maior do que a demanda dos animais, ocasionando excesso de fitomassa, a qual se acumula, e, ao completar o ciclo e a temperatura diminuir no outono-inverno, a forragem seca. Esse excesso de fitomassa seca dificulta o rebrote da pastagem. Em decorrência, a sobra de massa seca, normalmente, é manejada com fogo (Rheinheimer et al., 2003; Boldo et al., 2006). Portanto, nesses campos de altitude, no sul do Brasil, é frequente a queima dessa forragem, em campo nativo, motivada também por aspectos culturais.

A queima da forragem, além de favorecer o rebrote da pastagem propriamente dito, disponibiliza maior quantidade de massa vegetal menos fibrosa para os animais, após o rebrote (Cardoso et al., 2003). Assim, entre outros objetivos, o fogo é utilizado como prática 
de manejo da pastagem, visando facilitar e estimular o pastejo da forragem nativa por parte dos animais (Boldo et al., 2006). Com isso, a prática de queima da forragem nos campos nativos de elevada altitude no sul do Brasil, durante o inverno, facilita a disponibilidade de fitomassa para as estações seguintes. Portanto, a queima da forragem é prática comum para o manejo de pastagem nativa em Santa Catarina e no Rio Grande do Sul, especialmente na região fisiográfica denominada Campos de Cima da Serra, no Rio Grande do Sul (Fortes, 1960), e Campos do Planalto Sul Catarinense, em Santa Catarina, cujo objetivo principal é eliminar a fitomassa seca em razão das geadas durante o outono-inverno.

A queima da massa seca de pastagem nativa aumenta a disponibilidade de nutrientes devido à mineralização da fitomassa ocasionada pelo fogo (Boldo et al., 2006). É de se esperar, com isso, alterações dos teores de nutrientes no solo e na enxurrada decorrentes dessa queima. Em razão disso, aumenta a disponibilidade de nutrientes na camada superficial do solo no curto prazo (Coutinho, 1990), enquanto no longo prazo esse efeito é contrário (Boldo et al., 2006), devido às perdas do excesso de nutrientes, especialmente pela erosão hídrica.

Um dos maiores problemas decorrentes da queima da pastagem é o aumento da erosão hídrica pluvial devido à eliminação da cobertura do solo (Ferreira et al., 1997, 2008), com consequente transporte de nutrientes de plantas e de C orgânico, os quais poderão contaminar águas em mananciais de superfície, entre outros ambientes. Um dos principais impactos é o causado pelo $\mathrm{P}$, que, apesar de se encontrar em pequena quantidade na maioria dos solos brasileiros, é considerado o elemento-chave para ocorrência de eutrofização das águas de superfície. Para que isso ocorra, é necessário que esse elemento seja deslocado de seu ambiente natural, o solo, e chegue a um corpo d'água, o que normalmente ocorre por meio do escoamento superficial (Barbosa et al., 2009a). Outro elemento eutrofizante das águas de superfície é o nitrogênio (Barbosa et al., 2009b), embora menos problemático do que o $\mathrm{P}$, pois, em geral, não é limitante na maioria dos ambientes, já que as cianobactérias (algas azuis dos gêneros Anaboenna e Nostoc) e alguns outros microrganismos podem disponibilizar o nitrogênio na água ao retirá-lo diretamente da atmosfera (Sharpley et al., 1986, 1994; Correll, 1998). No caso do K perdido por erosão hídrica, seu conhecimento é importante para se saber quais os impactos causados pelo empobrecimento do solo no local de origem da erosão e pelo enriquecimento do ambiente no local de deposição do material erodido (Bertol et al., 2004).

Além disso, a alteração do equilíbrio dinâmico do ecossistema solo (Schacht, et al., 1996) é um fato notório. Claramente, a diminuição de cobertura do solo ocasionada pela queima da fitomassa resulta em diminuição de infiltração e de retenção de água no solo. O aumento do volume e da velocidade de enxurrada, decorrente do decréscimo da taxa de infiltração, explica o aumento das perdas de solo nas áreas queimadas, em relação às não queimadas (Hester et al., 1997).

O objetivo deste trabalho foi quantificar as perdas de água e solo por erosão hídrica e os teores e quantidades de $\mathrm{P}, \mathrm{Ke} \mathrm{NH}_{4}{ }^{+}$solúveis contidos na água de enxurrada sob chuva simulada, em campo nativo do sul do Brasil com e sem queima e com e sem adubação fosfatada.

\section{MATERIAL E MÉTODOS}

O trabalho foi conduzido em escala de campo, sob chuva simulada, em janeiro de 2008, em uma área experimental da Embrapa Uva e Vinho, unidade de Vacaria - RS. O terreno estava coberto por vegetação de campo nativo. As espécies vegetais predominantes eram gramíneas do gênero Andropogon, características da região. A área situa-se no nordeste do Estado do Rio Grande do Sul (latitude sul $28^{\circ} 30$ ', longitude $50^{\circ} 52$ ' a oeste de Greenwich). A altitude da região é de 966 m e o clima é do tipo Cfb, segundo a classificação de Köppen. O solo é um Latossolo Bruno aluminoférrico típico (Streck et al., 2008), o qual, na sua condição de campo nativo, apresenta as características, determinadas na camada de $0-10 \mathrm{~cm}$ (dados não publicados): $\mathrm{P}$ disponível: $2,05 \mathrm{mg} \mathrm{kg}{ }^{-1} ; \mathrm{K}$ trocável: $0,16 \mathrm{cmol}_{\mathrm{c}} \mathrm{kg}^{-1} ; \mathrm{pH}$ em água (1:1): 4,65; C orgânico total: $28,3 \mathrm{~g} \mathrm{~kg}^{-1}$; argila: $605 \mathrm{~g} \mathrm{~kg}^{-1}$; silte: $305 \mathrm{~g} \mathrm{~kg}^{-1}$; areia total: $90 \mathrm{~g} \mathrm{~kg}^{-1}$; densidade do solo: $1,05 \mathrm{~kg} \mathrm{dm}^{-3}$; e volume total de poros: $59,4 \%$.

Foram estudados dois tratamentos em relação à queima, em duas repetições: campo nativo sem queima da vegetação $(\mathrm{CN})$; e campo nativo com queima da vegetação $(\mathrm{CNq})$. Em uma das repetições de cada um desses tratamentos aplicaram-se $168 \mathrm{~kg} \mathrm{ha}^{-1} \mathrm{de}_{2} \mathrm{O}_{5}$ na forma de superfosfato triplo, caracterizando-se, assim, quatro tratamentos, sem repetição: campo nativo sem queima e sem adubo (CNs); campo nativo sem queima e com adubo (CNc); campo nativo com queima e sem adubo (CNqs); e campo nativo com queima e com adubo $(\mathrm{CNqc})$. A declividade do terreno nas parcelas era de $0,08 \mathrm{~m} \mathrm{~m}^{-1}$. A quantidade de massa vegetal da parte aérea do campo foi determinada do seguinte modo: em dois locais próximos de cada uma das parcelas experimentais, colheu-se a massa vegetal aérea em uma área de $0,36 \mathrm{~m}^{2}(0,6 \times 0,6 \mathrm{~m})$, até o nível do solo, a qual resultou em $9 \mathrm{t} \mathrm{ha}{ }^{-1}$ de massa seca em cada parcela. O adubo foi aplicado na superfície do solo, imediatamente após a queima e antes de iniciar a chuva simulada. Aplicou-se apenas adubação fosfatada, uma vez que o solo apresentava naturalmente baixo teor de $\mathrm{P}$ disponível $\left(2,05 \mathrm{mg} \mathrm{kg}^{-1}\right)$ na camada superficial, e esse elemento é o que maior risco oferece para a contaminação do ambiente do ponto 
de vista de eutrofização de águas. Optou-se por não aplicar adubo potássico, embora o teor desse elemento no solo fosse de $62,6 \mathrm{mg} \mathrm{kg}^{-1}$, devido ao baixo risco de contaminação ocasionado pelo $\mathrm{K}$ no ambiente, comparado ao $\mathrm{P}$. A queima da vegetação do campo foi realizada imediatamente antes do início da chuva. $\mathrm{Na}$ figura 1 apresentam-se as parcelas experimentais dos tratamentos sem queima e com queima da vegetação. As parcelas experimentais mediam $11 \mathrm{~m}$ de comprimento, no sentido da pendente, e $3,5 \mathrm{~m}$ de largura.

Sobre os tratamentos aplicou-se uma chuva simulada, com intensidade constante de $75 \mathrm{~mm} \mathrm{~h}^{-1} \mathrm{e}$ duração de $3 \mathrm{~h}$, totalizando uma lâmina de $225 \mathrm{~mm}$ de chuva, utilizando simulador de chuvas de braços rotativos (Swanson, 1965) (Figura 1) e água bombeada de um açude próximo à área experimental. A chuva aplicada caracterizou-se por apresentar um período de retorno maior do que o recomendado para o planejamento de terraços agrícolas para a região de Lages, SC (Cardoso et al., 1998), semelhante climaticamente à da região de Vacaria, RS. Optou-se por essa chuva porque o objetivo principal do trabalho era o de determinar teores e calcular quantidades de $\mathrm{P}, \mathrm{Ke} \mathrm{NH}_{4}{ }^{+}$na água da erosão. Para isso, foi aplicada uma chuva que proporcionasse um tempo de escoamento suficientemente longo e, assim, pudessem ser avaliados esses teores na erosão durante esse tempo. Para isso, foi necessário avaliar as perdas de água e solo e, com isso, aproveitando os dados de perda de água, objetivou-se também elaborar hidrogramas consistentes (sob taxa constante de infiltração de água no solo).

Imediatamente antes do início da chuva, coletaram-se amostras do solo na camada de $0-20 \mathrm{~cm}$, em dois pontos em cada parcela, para posterior determinação da umidade do solo em base gravimétrica. A partir do início da chuva, anotaramse os tempos de início e de pico da enxurrada.

Ao longo do período de escoamento, foram coletadas amostras de enxurrada, de acordo com o procedimento descrito em Cogo (1981), de cinco em cinco minutos a partir do seu início, para posterior determinação da concentração de sedimentos na enxurrada. Nessas mesmas amostras, posteriormente, foram calculadas a taxa máxima de enxurrada, as perdas totais de água e solo e a infiltração de água no solo. Nos mesmos tempos de coleta dessas amostras, coletaram-se outras amostras de enxurrada, conforme Bertol et al. (2007), para posterior determinação dos teores de $\mathrm{P}, \mathrm{Ke} \mathrm{NH}_{4}{ }^{+}$ solúvel. Com base nesses resultados, posteriormente, calcularam-se as perdas totais desses elementos na água de enxurrada.

A concentração de sedimentos na enxurrada, as perdas totais de água e solo, a infiltração de água no solo e a taxa máxima de enxurrada foram calculadas de acordo com os procedimentos descritos em Bertol et al. (1987). O teor de $\mathrm{P}$ solúvel na água de enxurrada foi determinado conforme Murphy \& Riley (1962), e o teor de K, por fotometria de chama, segundo Tedesco et al. (1995). O teor de $\mathrm{NH}_{4}{ }^{+}$na água da enxurrada foi determinado por meio de destilação direta do material, pelo método de Bremner \& Keeney (1966), modificado por Tedesco et al. (1995). Para determinação dos teores de $\mathrm{P}, \mathrm{Ke} \mathrm{NH}_{4}{ }^{+}$na água de enxurrada, procedeu-se à filtragem da água em filtro de $8,0 \mu \mathrm{m}$, de acordo com procedimento e justificativa descritos em Barbosa et al. (2009a). Para determinação dos teores de $\mathrm{P}, \mathrm{K} \mathrm{e} \mathrm{NH}_{4}{ }^{+}$na água do açude, seguiram-se os mesmos métodos utilizados para a água do escoamento superficial. As perdas totais desses elementos na água de enxurrada foram obtidas multiplicando-se os seus teores na água pela quantidade total de água perdida por erosão.
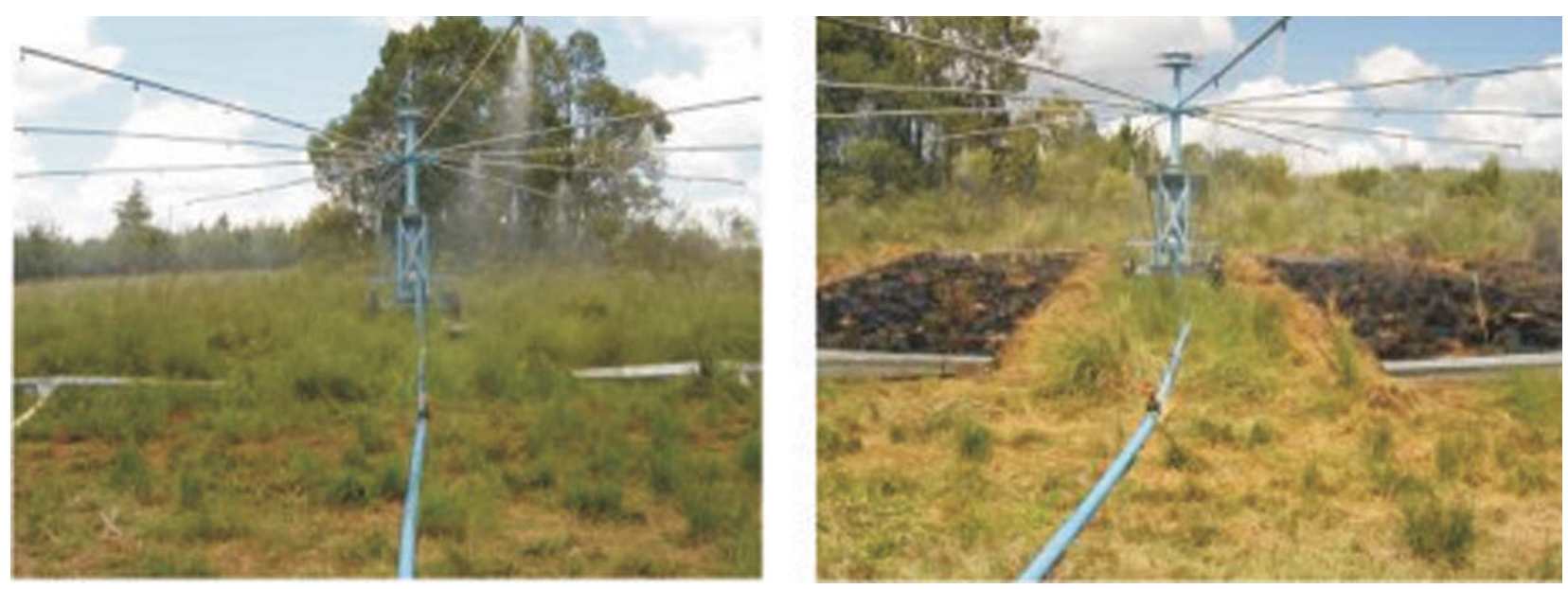

Figura 1. Simulador de chuva em operação sobre os tratamentos de campo nativo, sem queima da vegetação (esquerda) e com queima (direita), em um Latossolo Bruno aluminoférrico típico, em janeiro de 2008. 
Os dados, quando pertinentes, foram submetidos à análise de variância, utilizando-se o teste $\mathrm{F}$ a $5 \%$ de significância. Quando foi alcançada significância estatística, a diferença entre as médias foi conclusiva pelo teste $\mathrm{F}$. O modelo exponencial do tipo $\mathrm{y}=\mathrm{ae}^{\mathrm{bx}}$ foi utilizado para relacionar os teores de $\mathrm{P}, \mathrm{Ke} \mathrm{NH}_{4}{ }^{+}$na água da enxurrada com o tempo de ocorrência do escoamento superficial.

\section{RESULTADOS E DISCUSSÃO}

A queima da vegetação de campo nativo interferiu nas variáveis hidráulicas estudadas, em relação à ausência de queima, apesar de o teor de água no solo, no momento imediatamente anterior ao início da chuva, ter sido igual nos dois tratamentos (Quadro 1). A queima da vegetação antecipou o início do escoamento superficial de 60 para 15 min em relação ao tratamento sem queima. O pico da enxurrada foi antecipado de 178 para 118 min. A antecipação dos tempos de início e de pico do escoamento superficial no tratamento com queima contribuiu para o aumento do volume total de enxurrada, em comparação ao tratamento sem queima. A diminuição da cobertura do solo devido à queima da vegetação ocasionou aumento de $49 \%$ na taxa máxima de enxurrada em relação à ausência de queima, a qual aumentou de 39 para $58 \mathrm{~mm} \mathrm{~h}^{-1}$. Isso indica que houve influência da parte aérea da massa vegetal do campo nativo na interceptação e retenção superficial de água da chuva e na infiltração de água no solo. Além disso, a queima da fitomassa pode ter contribuído para a obstrução dos poros da superfície do solo, especialmente por partículas finas de cinzas, reduzindo a infiltração de água no solo. A perda total de água na forma de escoamento superficial foi elevada nos dois tratamentos, comparada ao volume de chuva aplicada, tendo sido aumentada pela queima da vegetação de 52 para $115 \mathrm{~mm}$, em relação à condição sem queima. Assim, o campo nativo queimado apresentou volume de enxurrada $120 \%$ maior do que o do não queimado, concordando com Hester et al. (1997) - o que é explicado pela diminuição da infiltração de água no solo de 173 para $110 \mathrm{~mm}$ devido à queima da vegetação do campo nativo.

A elevada perda total de água por escoamento superficial no campo natural, mesmo no caso do tratamento sem queima (Quadro 1), explica-se, em parte, pelo limite de infiltração de água no solo (Kohnke, 1968). Uma vez o solo saturado, a chuva excedente em relação à infiltração transforma-se em escoamento superficial, independentemente do manejo do solo. Contribuiu para a elevada perda de água o fato de ter sido aplicada uma chuva de longa duração, elevado volume e elevada intensidade. Assim, essa chuva foi suficiente para saturar o solo na sua camada superficial, provavelmente, e ocasionar elevada enxurrada.

A informação sobre o volume de enxurrada gerado é fundamental para o dimensionamento de obras hidráulicas destinadas ao manejo de solo. Embora seja pouco comum o manejo de água de escoamento superficial em áreas de campo nativo, é possível que isso passe a ser necessário devido à crise mundial de água, tanto em relação à qualidade quanto à quantidade disponível para o consumo dos seres vivos. Assim, é possível que obras hidráulicas de controle do escoamento superficial, como terraços, por exemplo, tradicionalmente utilizadas em áreas cultivadas, passem a ser praticadas também em áreas de campo nativo. A informação sobre o elevado volume de enxurrada que ocorreu nas duas condições de manejo, com e sem queima (Quadro 1), mostra que seria necessário aplicar práticas de suporte para controle do escoamento superficial, em ambas as condições. No entanto, na condição sob queima, a perda de água equivalente a $30,2 \mathrm{~m}^{3} \mathrm{ha}^{-1}$ foi 2,2 vezes maior do que na condição sem queima, a qual foi da ordem de $13,7 \mathrm{~m}^{3} \mathrm{ha}^{-1}$. E importante chamar a atenção para o fato de que essas perdas de água resultaram de uma única chuva, de longa duração, elevado volume e elevada intensidade. A altura dessa chuva $(225 \mathrm{~mm})$ é equivalente a $14 \%$ da altura anual das chuvas naturais da região. Portanto, o escoamento superficial decorrente dessa chuva não representou as perdas de água que poderiam ocorrer em consequência das chuvas que normalmente ocorrem durante um ano

Quadro 1. Variáveis hidráulicas obtidas em campo nativo com queima e sem queima sobre um Latossolo Bruno aluminoférrico típico, submetido a uma chuva simulada com intensidade constante de $75 \mathrm{~mm} \mathrm{~h}^{-1}$, duração de 180 min e lâmina de $225 \mathrm{~mm}$, em janeiro de 2008 - média das condições com adubo fosfatado e sem adubo

\begin{tabular}{|c|c|c|c|c|c|c|c|}
\hline Tratamento & Ug & $\mathbf{T i}$ & $\mathrm{Tp}$ & $q$ & QL & IA & QV \\
\hline & $\mathrm{kg} \mathrm{kg}^{-1}$ & 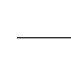 & - & $\mathrm{mm} \mathrm{h}^{-1}$ & 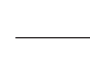 & - & $m^{3} h^{-1}$ \\
\hline $\mathrm{CN}$ & $0,40^{\mathrm{ns}}$ & $60^{*}$ & $178^{*}$ & $39^{*}$ & $52^{*}$ & $173^{*}$ & $13,7^{*}$ \\
\hline $\mathrm{CNg}$ & 0,40 & 15 & 118 & 58 & 115 & 110 & 30,2 \\
\hline
\end{tabular}

Ug: umidade gravimétrica; Ti: tempo de início da enxurrada; Tp: tempo de pico da enxurrada; q: taxa máxima de enxurrada; QL: lâmina de enxurrada perdida; IA: infiltração de água no solo; QV: volume de enxurrada perdida; CN: campo nativo sem queima; CNq: campo nativo com queima. Efeito dentro de cada coluna: ${ }^{(n s)}$ não significativo; ${ }^{*}$ ) significativo pelo teste $\mathrm{F}$ a $5 \%$. 
nessa região. A precipitação pluvial média anual dessa região é de aproximadamente $1.600 \mathrm{~mm}$, podendo precipitar cerca de $2.500 \mathrm{~mm}$ em determinados anos, com grande parte desse volume concentrada em poucos meses (Bertol, 1993; Bertol et al., 2002). No mês de janeiro, no qual este trabalho foi realizado, a altura média de chuva na região é de $154 \mathrm{~mm}$, podendo atingir o valor de $364 \mathrm{~mm}$, conforme Bertol et al. (2002).

O histórico da taxa de enxurrada foi distinto nos dois tratamentos estudados (Figura 2). O hidrograma mostrou que no tratamento com queima da vegetação a taxa de enxurrada aumentou mais rapidamente do que naquele sem queima até o momento do pico da enxurrada. O crescimento mais lento da taxa de enxurrada no tratamento sem queima foi influenciado, possivelmente, pelo volume de água interceptado e armazenado na parte aérea da vegetação.

Os valores de concentração de sedimentos na enxurrada e de perdas totais de solo foram baixos e variaram nos dois tratamentos estudados (Quadro 2). No tratamento com queima da vegetação, a concentração de sedimentos, da ordem de $0,1744 \mathrm{~g} \mathrm{~L}^{-1}$, foi 4,7 vezes maior do que no tratamento sem queima, que foi de $0,0371 \mathrm{~g} \mathrm{~L}^{-1}$. A perda total de solo foi 8,9 vezes maior no tratamento com queima $\left(147,88 \mathrm{~kg} \mathrm{ha}^{-1}\right)$ do que no sem queima $\left(16,66 \mathrm{~kg} \mathrm{ha}^{-1}\right)$. A menor concentração de sedimentos na enxurrada e a perda total de solo no tratamento sem queima são explicadas pela proteção do solo exercida pela parte aérea da vegetação de campo contra a energia cinética da chuva e da enxurrada. No tratamento com queima, observase (Figura 1) que as soqueiras da vegetação restantes na superfície do solo após a queima constituíam ainda

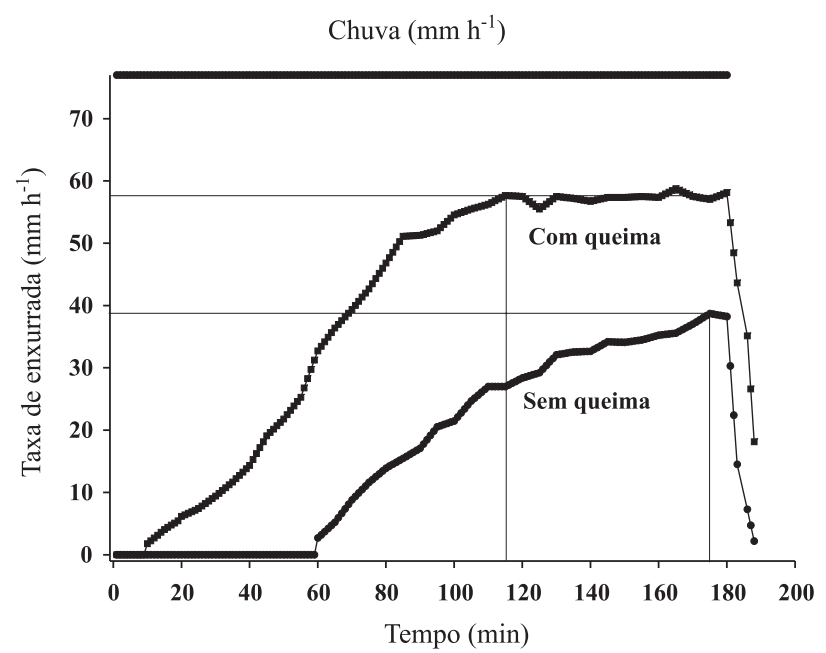

Figura 2. Hidrograma obtido em campo nativo com queima e sem queima sobre um Latossolo Bruno aluminoférrico típico submetido a uma chuva simulada com intensidade constante de $75 \mathrm{~mm} \mathrm{~h}^{-1}$, duração de 180 min e lâmina de $225 \mathrm{~mm}$, em janeiro de 2008 - média das condições com adubo fosfatado e sem adubo.
Quadro 2. Concentração de sedimentos na enxurrada (CS) e perda total de solo (PS) por erosão hídrica obtida em campo nativo com queima e sem queima sobre um Latossolo Bruno aluminoférrico típico, submetido a uma chuva simulada com intensidade constante de $75 \mathrm{~mm} \mathrm{~h}^{-1}$, duração de $180 \mathrm{~min}$ e lâmina de $225 \mathrm{~mm}$, em janeiro de 2008 - média das condições com adubo fosfatado e sem adubo

\begin{tabular}{ccc}
\hline Tratamento & CS & PS \\
\hline & $\mathrm{g} \mathrm{L}^{-1}$ & $\mathrm{~kg} \mathrm{ha}^{-1}$ \\
$\mathrm{CN}$ & $0,0371^{*}$ & $16,66^{*}$ \\
$\mathrm{CNq}$ & 0,1744 & 147,88 \\
\hline
\end{tabular}

CN: campo nativo sem queima; CNq: campo nativo com queima. Efeito dentro de cada coluna: ${ }^{(n s)}$ não significativo; ${ }^{(*)}$ significativo pelo teste $\mathrm{F}$ a $5 \%$.

elevada quantidade de fitomassa, a qual possivelmente ainda protegia a superfície do solo contra a energia erosiva da chuva e da enxurrada. Além disso, a boa condição física do solo, em função da estrutura em condição natural em ambos os tratamentos, condicionou elevada estabilidade de agregados, a qual foi determinada por Gobbi (2009). A diferença no valor de perda de solo, menor no tratamento sem queima em relação ao com queima, é explicada principalmente pela cobertura do solo ocasionada por 9 t ha-1 de massa vegetal no tratamento sem queima, que influenciou também a perda de água na forma de enxurrada.

A concentração de sedimentos na enxurrada foi influenciada pelo tempo de chuva e pela queima da massa vegetal do campo (Figura 3). Após um período inicial de aumento da concentração de sedimentos na enxurrada, devido ao aumento da taxa de fluxo superficial até este atingir o pico, a referida concentração diminuiu, de forma irregular, até o final da chuva em ambos os tratamentos. Assim, no tratamento com queima, a concentração de sedimentos na enxurrada variou entre o máximo de 0,33 $\mathrm{g} \mathrm{L}^{-1}$, aos $28 \mathrm{~min}$ de ocorrência de enxurrada, e o mínimo de $0,06 \mathrm{~g} \mathrm{~L}^{-1}$, aos $150 \mathrm{~min}$, ao passo que no tratamento sem queima essa variação situou-se entre o máximo de $0,14 \mathrm{~g} \mathrm{~L}^{-1}$, aos $70 \mathrm{~min}$, e o mínimo de $0,01 \mathrm{~g} \mathrm{~L}^{-1}$, aos 160 e $170 \mathrm{~min}$. O comportamento irregular da concentração de sedimentos na enxurrada ao longo da ocorrência de escoamento superficial, bem como o aumento inicial até o pico da enxurrada e, posteriormente, a diminuição até o final da chuva, é normal, de acordo com Bertol (1995) e Gobbi (2009).

Os teores de $\mathrm{P}$ na água da enxurrada foram maiores no tratamento adubado com $\mathrm{P}$ do que no não adubado e no tratamento com queima do que no sem queima, na média da duração da enxurrada (Quadro 3). No tratamento com queima, o teor do elemento foi 5,2 vezes maior no tratamento adubado do que no não adubado. No campo sem queima, por 


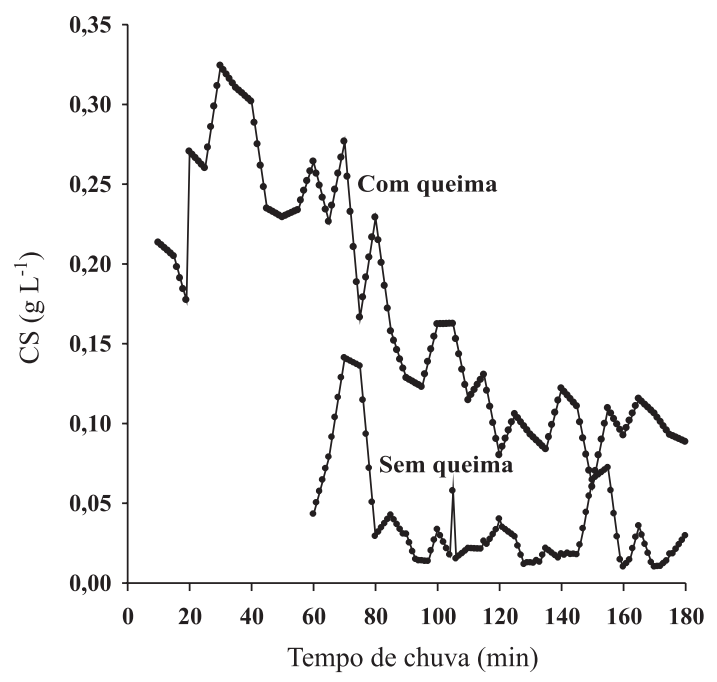

Figura 3. Concentração de sedimentos na enxurrada (CS) obtida em campo nativo com queima e sem queima sobre um Latossolo Bruno aluminoférrico típico, submetido a uma chuva simulada com intensidade constante de $75 \mathrm{~mm} \mathrm{~h}^{-1}$, duração de 180 min e lâmina de 225 mm, em janeiro de 2008 - média das condições com adubo fosfatado e sem adubo (repetições).

Quadro 3. Teores médios e perdas totais de fósforo, potássio e amônio solúvel na água de enxurrada em campo nativo com queima e sem queima e com adubo fosfatado e sem adubo, sobre um Latossolo Bruno aluminoférrico típico submetido a uma chuva simulada com intensidade constante de $75 \mathrm{~mm} \mathrm{~h}^{-1}$, duração de 180 min e lâmina de 225 mm, em janeiro de 2008 - média das coletas durante a enxurrada

\begin{tabular}{|c|c|c|c|}
\hline Tratamento & $\mathbf{P}$ & $\mathbf{K}$ & $\mathrm{NH}_{4}^{+}$ \\
\hline & & $-\mathrm{mg} \mathrm{L}^{-1}$ & \\
\hline $\mathrm{CNc}$ & 0,097 & 3,81 & 0,452 \\
\hline $\mathrm{CNs}$ & 0,020 & 3,81 & 0,441 \\
\hline $\mathrm{CNqc}$ & 3,301 & 36,45 & 1,950 \\
\hline \multirow[t]{2}{*}{$\mathrm{CNqs}$} & 0,640 & 37,11 & 1,968 \\
\hline & & $-\mathrm{g} \mathrm{ha}^{-1}$ & \\
\hline $\mathrm{CNc}$ & 1,329 & 52,20 & 6,192 \\
\hline $\mathrm{CNs}_{\mathrm{s}}$ & 0,274 & 52,20 & 6,042 \\
\hline $\mathrm{CNqc}$ & 99,690 & $1.100,79$ & 58,890 \\
\hline CNqs & 19,328 & $1.120,72$ & 59,434 \\
\hline
\end{tabular}

CNc: campo nativo sem queima e com adubo; CNs: campo nativo sem queima e sem adubo; CNqc: campo nativo com queima e com adubo; CNqs: campo nativo com queima e sem adubo.

outro lado, a adubação fosfatada aumentou em 4,9 vezes o teor de $\mathrm{P}$ na água da enxurrada, em relação ao não adubado. Esses aumentos foram ocasionados pela adubação fosfatada adicionada ao solo, unicamente. A queima da fitomassa propiciou aumento de 34 vezes no teor de $\mathrm{P}$ na água da enxurrada, em relação à ausência de queima, na média dos tratamentos adubado e não adubado, o que é explicado unicamente pela queima, conforme argumentado por Coutinho (1990). Especialmente na condição de queima e com adubo, o teor de $\mathrm{P}$ na água da enxurrada foi elevado quando comparado com o teor normalmente encontrado nesse solo em condições naturais $\left(2,05 \mathrm{mg} \mathrm{kg}^{-1}\right)$. Nos demais casos (tratamento sem queima com e sem adubo e com queima sem adubo), o teor do elemento na água da enxurrada foi elevado em comparação com o teor observado na água em condições naturais, conforme verificado por Barbosa et al. (2009a). Vollenweider (1971) sugeriu 0,01 $\mathrm{mg} \mathrm{L}^{-1}$ como o nível crítico de $\mathrm{P}$ solúvel na água, isto é, se a concentração de $\mathrm{P}$ exceder esse valor nos lagos e reservatórios, pode ocorrer eutrofização.

No caso do K, os teores foram influenciados apenas pela queima (Quadro 3), devido ao fato de não ter sido aplicada adubação com esse elemento. Assim, a queima da vegetação aumentou em 9,6 vezes o teor de K na água da enxurrada, em comparação à ausência de queima. Portanto, a queima da vegetação influenciou menos a mineralização de $\mathrm{K}$ do que a de $\mathrm{P}$, em relação à ausência de queima, aumentando mais a disponibilidade de $\mathrm{P}$ do que a de $\mathrm{K}$ para ser transportado pela enxurrada.

A presença de $\mathrm{NH}_{4}{ }^{+}$na água da enxurrada foi 4,4 vezes maior quando a vegetação foi queimada do que na ausência de queima (Quadro 3), tendo sido influenciada também só pela queima, pelo mesmo motivo justificado no caso do K. A diferença entre queima e não queima foi menor para o amônio do que para o $\mathrm{K}$ e, principalmente, para o $\mathrm{P}$, devido, provavelmente, à maior volatilização de nitrogênio pela ação da queima do que para os outros dois elementos.

A queima proporcionou aumento dos valores de $\mathrm{P}$, $\mathrm{K}$ e amônio em relação à ausência de queima; o mesmo ocorreu com a adubação fosfatada, em relação à condição sem adubo, para o caso do P. O P é o principal causador de eutrofização das águas superficiais, sobretudo em ambiente lêntico (McIsaac et al., 1995). Embora a quantidade de $\mathrm{P}$ perdido na água da enxurrada possa parecer pequena, foi expressiva especialmente na presença de queima, já que essa quantidade é decorrente de apenas uma chuva erosiva. No caso do K, a perda total foi elevada na condição com queima, ultrapassando $1 \mathrm{~kg} \mathrm{ha}^{-1}$, o que demonstra a facilidade de transporte desse elemento pela água de enxurrada nessa condição de manejo do campo nativo.

Os teores de $\mathrm{P}, \mathrm{K}$ e $\mathrm{NH}_{4}{ }^{+}$contidos na água da enxurrada diminuíram exponencialmente do início ao final do escoamento superficial (Figuras 4, 5 e 6). No caso do $\mathrm{P}$ (Figura 4), o teor inicial de $5,5 \mathrm{mg} \mathrm{L}^{-1}$ decresceu para 1,2 $\mathrm{mg} \mathrm{L}^{-1}$ no final do escoamento, na condição em que o tratamento com queima foi adubado, enquanto no tratamento com queima e sem adubo o valor inicial foi de 1,2 $\mathrm{mg} \mathrm{L}^{-1}$, e o final, de $0,2 \mathrm{mg} \mathrm{L}^{-1}$. 
Para o tratamento sem queima, houve pequena diferença entre as condições com adubo e sem adubo apenas nos instantes iniciais do escoamento, cujo teor foi de $0,2 \mathrm{mg} \mathrm{L}^{-1}$ no início na condição com adubo, tendendo a zerar o teor ao final do escoamento, ao passo que, na condição sem adubo, os teores foram muito próximos de zero desde o início do escoamento até o final. A diminuição dos teores de $\mathrm{P}, \mathrm{K} \mathrm{e} \mathrm{NH}_{4}{ }^{+}$ na água da enxurrada ao longo do tempo de escoamento superficial é normal, conforme resultados obtidos também por Bertol et al. (2007) e Barbosa et al. (2009a,b). Esse comportamento é explicado pelo fato de que os teores dos elementos $\mathrm{P}$ e $\mathrm{K}$ e do $\mathrm{NH}_{4}{ }^{+}$ são maiores no solo no início do escoamento superficial e, por isso, eles são transportados em maior quantidade pelo escoamento. Além disso, há efeito de diluição, pois no início do escoamento a taxa de enxurrada é menor do que no final.

Os teores de $\mathrm{P}$ na água da enxurrada foram expressivamente elevados comparados com os verificados nas águas de lagos e rios em condições naturais dessa região, os quais são em geral < 0,01 $\mathrm{mg} \mathrm{L}^{-1}$ (Bertol et al., 2007; Barbosa et al., 2009a). Isso ocorreu especialmente no tratamento com queima adubado, bem como no tratamento com queima não adubado, em ambos durante o período inteiro de duração do escoamento, e no campo sem queima adubado nos instantes iniciais de ocorrência da enxurrada (Figura 4). Assim, tanto a queima quanto

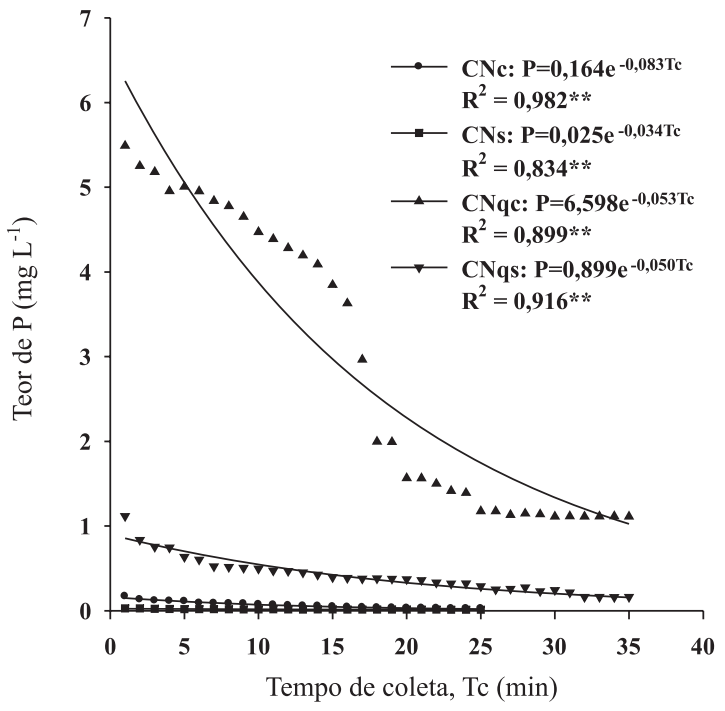

Figura 4. Relação dos teores de fósforo na água de enxurrada com o tempo de coleta, Tc, obtidos em campo nativo sem queima e com adubo (CNc), sem queima e sem adubo (CNs), com queima e com adubo (CNqc) e com queima e sem adubo (CNqs), sobre um Latossolo Bruno aluminoférrico típico, submetido a uma chuva simulada com intensidade constante de $75 \mathrm{~mm} \mathrm{~h}^{-1}$, duração de $180 \mathrm{~min}$ e lâmina de $225 \mathrm{~mm}$, em janeiro de 2008.

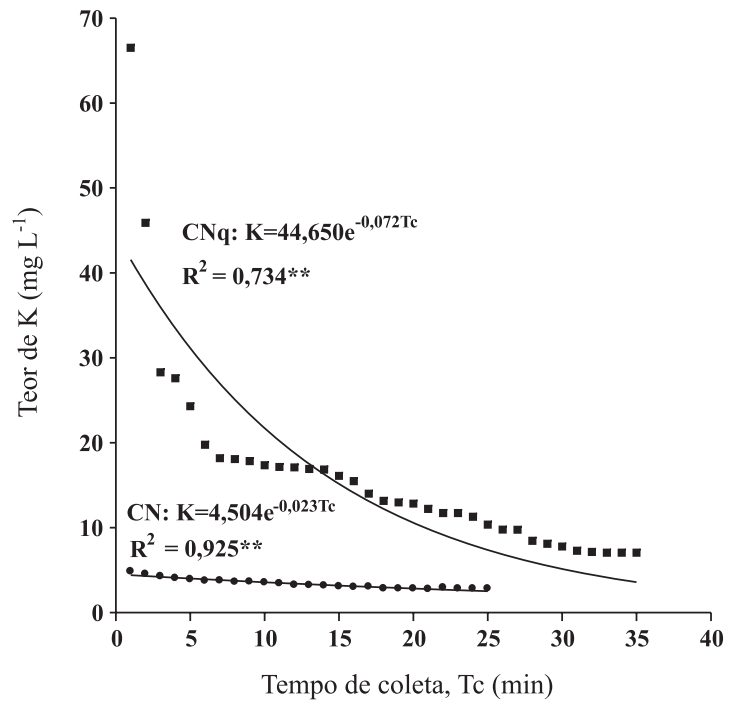

Figura 5. Teores de potássio na água de enxurrada, obtidos em campo nativo com queima ( $\mathrm{CNq})$ e sem queima (CN) sobre um Latossolo Bruno aluminoférrico típico, submetido a uma chuva simulada com intensidade constante de $75 \mathrm{~mm} \mathrm{~h}^{-1}$, duração de $180 \mathrm{~min}$ e lâmina de $225 \mathrm{~mm}$, em janeiro de 2008 - média das condições com adubo fosfatado e sem adubo.

a adubação do campo nativo são potencialmente perigosas do ponto de vista de disponibilizar o transporte de P no escoamento superficial em eventos de erosão hídrica. Elevados teores de P na água da enxurrada foram verificados também por Miras Avalos et al. (2009), trabalhando com várias doses de resíduo cultural de milho em um Cambissolo sob chuva simulada. Esse elemento, em concentrações elevadas no fluxo de água, pode eutrofizar os mananciais, especialmente aqueles em regime lêntico.

Os teores de $\mathrm{K}$ (Figura 5) e de $\mathrm{NH}_{4}{ }^{+}$(Figura 6) na água da enxurrada foram muito elevados nas duas primeiras amostras de escoamento superficial no tratamento com queima, em relação aos teores encontrados nas amostras coletadas posteriormente e também em relação aos teores no tratamento sem queima. Isso mostra que os primeiros momentos de escoamento superficial da água da chuva são responsáveis pelo transporte de grande parte desses elementos solúveis na água, em especial sob chuvas de elevada intensidade sobre o tratamento com queima. No final do escoamento, ou seja, ao final de três horas de chuva, os teores de $\mathrm{K}$ e de $\mathrm{NH}_{4}{ }^{+}$na água da enxurrada ainda eram relativamente elevados no tratamento com queima em relação ao sem queima: na faixa de $10 \mathrm{mg} \mathrm{L}^{-1}$ para o K e de $0,5 \mathrm{mg} \mathrm{L}^{-1}$ para o amônio. Isso demonstra o efeito prejudicial da queima do campo na mineralização de K e amônio e preocupa especialmente do ponto de vista de perda desses elementos, com consequente empobrecimento do solo no local da erosão. No tratamento sem queima, os 


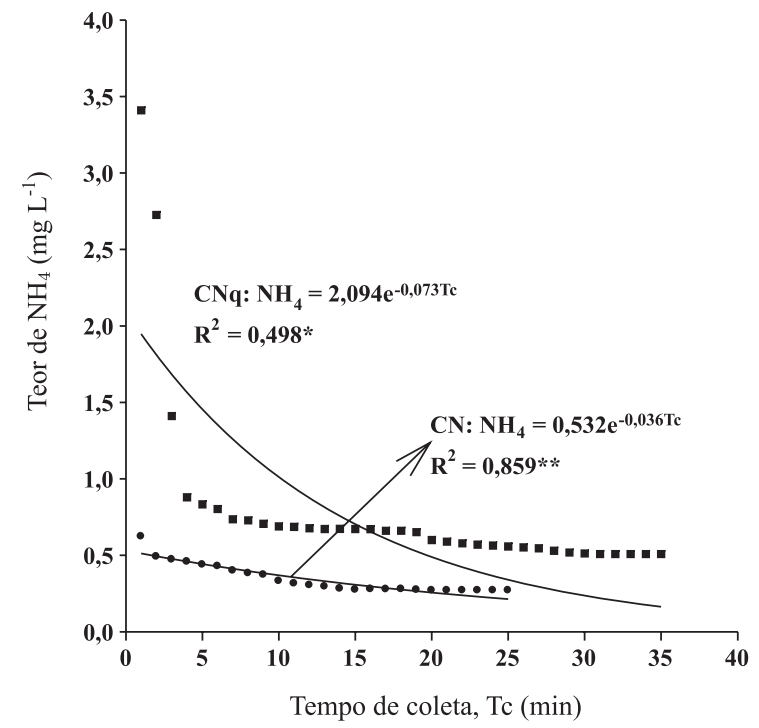

Figura 6. Teores de $\mathrm{NH}_{4}^{+}$na água de enxurrada, obtidos em campo nativo com queima $(\mathrm{CNq})$ e sem queima $(\mathrm{CN})$ sobre um Latossolo Bruno aluminoférrico típico, submetido a uma chuva simulada com intensidade constante de $75 \mathrm{~mm} \mathrm{~h}^{-1}$, duração de 180 min e lâmina de $225 \mathrm{~mm}$, em janeiro de 2008 - média das condições com adubo fosfatado e sem adubo.

teores de $\mathrm{K}$ e de $\mathrm{NH}_{4}{ }^{+}$na água da enxurrada foram expressivamente menores do que com queima. Mesmo assim, os elementos foram transportados, devido à sua disponibilidade na superfície do solo e solubilidade em água. Elevados teores de K na água da enxurrada em semeadura direta foram observados também por Bertol et al. (2007), trabalhando com experimento de erosão sob chuva simulada em um Nitossolo Háplico. Barbosa et al. (2009b), trabalhando com experimento de erosão sob chuva simulada em um Cambissolo Húmico, e Miras Avalos et al. (2009), ambos trabalhando em experimento de erosão sob chuva simulada sobre um Cambissolo e doses de resíduo de milho, observaram elevados teores de $\mathrm{NH}_{4}{ }^{+}$na água da enxurrada. Assim, o modelo exponencial do tipo $\mathrm{y}=\mathrm{a} \mathrm{e}^{-\mathrm{bx}}$ ajustou-se aos teores de $\mathrm{P}, \mathrm{K}$ e $\mathrm{NH}_{4}{ }^{+}$na água da enxurrada, em relação ao tempo de ocorrência do escoamento superficial $(p<0,01)$.

\section{CONCLUSÕES}

1. A queima da matéria seca do campo nativo diminui os tempos de início e pico da enxurrada e a infiltração de água no solo, bem como aumenta a taxa máxima de enxurrada, as perdas de água e solo por erosão hídrica e os teores e as perdas totais de $\mathrm{P}, \mathrm{K}$ e $\mathrm{NH}_{4}{ }^{+}$na água de enxurrada, em relação à ausência da queima.
2. A concentração de sedimentos na enxurrada é maior no tratamento com queima da matéria seca do que no sem queima. O maior e o menor valor da concentração de sedimentos ocorrem em menor tempo de duração do escoamento superficial no tratamento com queima do que no tratamento sem queima, contribuindo para que a perda total de solo seja 8,9 vezes maior com a queima do que sem a queima do campo.

3. O teor e a perda total de $\mathrm{P}$ na água da enxurrada são maiores no tratamento com adubo fosfatado do que no tratamento sem adubo, tanto no tratamento com queima quanto no sem queima. Para o $\mathrm{K}$ e o $\mathrm{NH}_{4}^{+}$, os teores e as perdas totais são maiores no tratamento com queima do que no sem queima.

4. $\mathrm{O}$ modelo exponencial do tipo $\mathrm{y}=\mathrm{ae} \mathrm{e}^{-\mathrm{bx}}$ ajusta-se aos teores de $\mathrm{P}, \mathrm{K} \mathrm{e} \mathrm{NH}_{4}{ }^{+}$na água da enxurrada, em relação ao tempo de ocorrência do escoamento superficial $(p<0,01)$.

\section{LITERATURA CITADA}

BARBOSA, F.T.; BERTOL, I.; LUCIANO, R.V. \& PAZ GONZÁLEZ, A. Phosphorus losses in water and sediments in runoff of the water erosion in oat and vetch crops seed in contour and downhill. Soil Tillage Res., 106:22-28, 2009a.

BARBOSA, F.T.; BERTOL，I.; LUCIANO, R.V.; PAZ GONZÁlEZ, A. \& VIDAL VÁZQUEZ, E. Teor de nitrogênio solúvel na água de erosão hídrica em cultura de aveia e ervilhaca em três formas de semeadura. R. Bras. Ci. Solo, 33:439-446, 2009b.

BERTOL, I. Índice de erosividade $\left(\mathrm{EI}_{30}\right)$ para Lages $(\mathrm{SC})-1^{\mathrm{a}}$ aproximação. Pesq. Agropec. Bras., 28:515-521, 1993.

BERTOL, I. Comprimento crítico de declive para preparos conservacionistas de solo. Porto Alegre, Universidade Federal do Rio Grande do Sul, 1995. 185p. (Tese de Doutorado)

BERTOL, I.; COGO, N.P. \& LEVIEN, R. Relações da erosão hídrica com métodos de preparo do solo, na ausência e na presença de cobertura por resíduo cultural de trigo. R. Bras. Ci. Solo, 11:187-192, 1987.

BERTOL, I.; ENGEL, F.L.; MAFRA, A.L.; BERTOL, O.J. \& RITTER, S.R. Phosphorus, potassium and organic carbon concentrations in runoff water and sediments under different soil tillage systems during soybean growth. Soil Tillage Res., 94:142-150, 2007.

BERTOL, I.; LEITE, D.; GUADAGNIN, J.C. \& RITTER, S.R. Erosão hídrica em um Nitossolo Háplico submetido a diferentes sistemas de manejo sob chuva simulada. II Perdas de nutrientes e carbono orgânico. R. Bras. Ci. Solo, 28:1045-1054, 2004.

BERTOL, I.; SCHICK, J.; BATISTELA, O.; LEITE, D.; VISENTIN, D. \& COGO, N.P. Erosividade das chuvas e sua distribuição entre 1989 e 1998 no município de Lages (SC). R. Bras. Ci. Solo, 26:455-464, 2002. 
BOLDO, E.L.; BRUNETTO, A.; SIMIONI, G.L.; SARTORI, M.; BUTZKE, A.; SPECHT, A.; LOVATEL, J.L.; SCUR, L. \& WASUM, R.A. O uso do fogo como prática agropastoril na microrregião homogênea dos campos de cima da serra: análise da situação atual e busca de um modelo sustentável. R. Bras. Agroec., 1:875-878, 2006.

BREMNER, J.M. \& KEENEY, D.S. Determination and isotope ratio analysis of different forms of Nitrogen is soils: 3 . Exchangeable ammonium, nitrate e nitrite by extraction - distillation methods. Soil Sci. Soc. Am. Proc., 30:577$582,1966$.

CARDOSO, C.O.; ULLMANN, M.N. \& BERTOL, I. Análise de chuvas intensas a partir da desagregação de chuvas diárias de Lages e de Campos Novos (SC). R. Bras. Ci. Solo, 22:131-140, 1998.

CARDOSO, E.L.; CRISPIM, S.M.A.; RODRIGUES, C.A.G. \& BARIONI JR., W. Efeitos da queima na dinâmica da biomassa aérea de um campo nativo no Pantanal. Pesq. Agropec. Bras., 38:747-752, 2003.

COGO, N.P. Effect of residue cover, tillage induced roughness, and slope length on erosion and related parameters. West Lafayette, Purdue University, 1981. 346p. (Tese de Doutorado)

COUTINHO, L.M. O Cerrado e a ecologia do fogo. Ci. Hoje, 12:22-30, 1990.

CORRELL, D.L. The role of phosphorus in the eutrophication of receiving waters: A review. J. Environ. Qual., 27:26166, 1998.

FERREIRA, A.J.D.; COELHO, C.O.A.; SHAKESBY, R.A. \& WALSH, R.P.D. Sediment and solute yield in forest ecosystems affected by fire and rip-ploughing techniques, Central Portugal: a plot and catchment analysis approach. Phys. Chem. Earth, 22:309-314, 1997.

FERREIRA, A.J.D.; COELHO, C.O.A.; RITSEMA, C.J.; BOULET, A.K. \& KEISER, J.J. Soil and water degradation processes in burned areas: Lessons learned from a nested approach. Catena, 74:273-285, 2008.

FORTES, A.B. Compêndio de geografia geral do Rio Grande do Sul. Porto Alegre, Sulina, 1960. 108p.

GOBBI, E. Erosão hídrica em pomar de maçã sob diversas formas de manejo do solo comparadas ao campo natural. Lages, Universidade do Estado de Santa Catarina, 2009. 74p. (Tese de Mestrado)

HESTER, J.W.; THUROW, T.L. \& TAYLOR JR., C.A. Hydrologic characteristics of vegetation types as affected by prescribed burning. J. Range Manag., 50:199-204, 1997.
KOHNKE, H. Soil physics. New York, McGraw - Hill, 1968. $224 \mathrm{p}$.

MCISAAC, G.F.; MITCHELL, J.K. \& HIRSCHI, M.C. Dissolved phosphorus concentrations in runoff from simulated rainfall on corn and soybean tillage systems. J. Soil Water Conserv., 50:383-387, 1995.

MIRÁS AVALOS, J.M.; SANDE FOUZ, P.; VIDAL VÁZQUEZ, E.; PAZ GONZÁLEZ, A. \& BERTOL, I. Crop residue effects on organic carbon, nitrogen, and phosphorus concentrations and loads in runoff water. Comm. Soil Sci. Plant Anal., 40:200-213, 2009.

MURPHY, J. \& RILEY, J.P. A modified single solution method for determination of phosphate in natural waters. Anal. Chim. Acta, 26:31-36, 1962.

RHEINHEIMER, D.S.; SANTOS, J.C.P.; FERNANDES, V.B.B.; MAFRA, A.L. \& ALMEIDA, J.A. Modificações nos atributos químicos de solo sob campo nativo submetido à queima. Ci. Rural, 33:49-55, 2003.

SCHACHT, W.H.; STUBBENDIECK, J.; BRAGG, T.B.; SMART, T.J. \& DORAN, J.W. Soil quality response of reestablished grasslands to mowing and burning. J. Range Manag., 49:458-463, 1996.

SHARPLEY, A.; SMITH, S.J. \& NANEY, J.W. Environmental impact of agricultural nitrogen and phosphorus use. Am. Chem. Soc., 20:173-179, 1986.

SHARPLEY, A.N.; CHAPRA, S.C.; WEDEPOHL, R.; SIMS, J.T.; DANIEL, T.C. \& REDDY, K.R. Managing agricultural phosphorus for protection of surface waters: Issue and options. J. Environ. Qual., 23:437-451. 1994.

STRECK, E.V.; KÄMPF, N.; DALMOLIN, R.S.D.; KLAMT, E.; NASCIMENTO, P.C.; SCHNEIDER, P.; GIASSON, E. \& PINTO, L.F.S. Solos do Rio Grande do Sul. 2.ed. Porto Alegre, EMATER/RS-ASCAR, 2008. 222p.

SWANSON, N.P. A rotating-boom rainfall simulator. Am. Soc. Agric. Eng., 8:71-72, 1965.

TEDESCO, M.J.; GIANELLO, C.; BISSANI, C.A.; BOHNEN, H. \& VOLKWEISS, S.J. Análise de solos, plantas e outros materiais. 2.ed. Porto Alegre, Universidade Federal do Rio Grande do Sul, 1995. 174p.

VOLLENWEIDER, R.A. Scientific fundamentals of the eutrophication of lakes and flowing waters, with particular reference to nitrogen and phosphorus as factors in eutrophication. Paris, Organization for Economic Cooperation and Development (OECD), 1971. Technical Report. 